\title{
I: 10.53469/jgebf.2022.04(01).12 \\ The Important Position and Function of Education in Cultivating Female Entrepreneurs
}

\author{
Huamber Veena \\ Department of Commerce, Dr. Babasaheb Ambedkar Marathwada University, Aurangabad 431001, India
}

\begin{abstract}
The study indicates that the education has showed the ways of uplifting the standard of living among the women's. Acceleration due to education will bring about a full transformation of India's women entrepreneurship landscape. Education to women will put India at par with several emerging and advanced economies where more than $40 \%$ of all enterprises will be womenowned. The Covid-19 pandemic presents opportunity for young women entrepreneurs to start their new enterprise which will not put burden on shocks in the future. Numerous opportunities have emerged related to health care, financial instruments, education, supply chains, entertainment and culture. These are some of the sectors in need of innovative ideas and developments in the current situation where a women's of $21^{\text {st }}$ century can emerge as successful entrepreneurs.
\end{abstract}

Keywords: Entrepreneur, Enterprises, Empowerment, Education, COVID-19

\section{Introduction}

Today's women of $21^{\text {st }}$ century are capable of doing work equally as compared to men. They are empowering themselves by taking higher education and are ahead in various fields. They try to face challenges and solve difficulties without getting disturbed in every walk of life. Entrepreneurship is about taking a calculated risk and multitasking. It is about understanding people and guiding them towards a goal. Women are naturally gifted in all these aspects, hence entrepreneurship is one of the best professions for women. From setting up a small store and a business out of home to setting up an IT company and an innovative start-up, women are there in every conceivable sector.

Education is the most powerful tool to alter women's position in society. If women do not have access to education, then they will have no access to information and will be unable to participate in public debates and unaware of their rights. Education is regarded as an essential milestone of women empowerment because it enables them to face challenges, to confront their traditional role and change their lifestyle. Large women folk of India are illiterate, backward, weak, and exploited. Education reduces inequalities and functions as a means of improving their status within the family. India can transform into a developed country only if women contribute to the best of her capacity and ability which is possible when she is educated and empowered.

Empowering women with education provides women with various avenues to acquire knowledge and get stable in improving her family standard of living. Empowerment develops the capacity in women to influence decisionmaking process, planning, implementation and evaluation by integrating them into successful citizens. It enables them to represent their interests in a responsible and self-determined way, acting on their own authority. Empowerment can be viewed as means of creating a social environment in which one can make decisions and make choices either individually or collectively for social transformation. Empowerment strengthens the internal ability by way of acquiring knowledge, power and experience.

In developing economies, the role of women is most significant as job creators and workers. In India, female entrepreneur's activity is concentrated in the informal sector with limited potential for growth in income and employment. In the Indian situation, female entrepreneurs are unable to grow their business from micro or small to medium or large productive enterprises with transformed economic impact.

Entrepreneurship among women has the power to create positive outcomes for individuals, societies and economies. Entrepreneurship enables women to play a pivotal rather than a peripheral role in the economic sphere.

Speaking about economic outcomes, women entrepreneurs create jobs for themselves and others. About personal outcomes, these entrepreneurs generate autonomy and create control on themselves. Discussing about social outcomes, women entrepreneurs become source of example for other women's who are seeking to and have potential to become entrepreneurs. Women entrepreneurs have potential to create new ideas and innovation for new needs and opening up new markets.

\section{Objectives of the Study}

The following objectives were framed for the study:

1) To study the role and importance of education in empowering women of Maharashtra.

2) To know the current status of women entrepreneurs.

3) To identify the factors acting as constraints in the path of women entrepreneurship.

4) To suggest various measures for empowering women entrepreneurs.

\section{Methodology}

The present study uses the collection of data from secondary sources. Secondary data is from various published reports, 
census and unpublished records, books, magazines and journals, both print and online.

\section{Conceptual and Operational Framework:}

Women's contribution plays a vital part in the growth of the nation, but women suffer many constraints affecting their personal and national development, overlooking women in the development course institutes a waste of human resources. While the status of women has dramatically risen over the years but the majority of women remain economically and socially marginalized due to illiteracy, ignorance, traditional and orthodox system of society. Education provides sufficient and realistic sustenance for women, promoting a gender-neutral environment in all aspects of leading to empowerment of women. Empowerment of women increases her proficiencies towards decision-making and ability to bear the risk.

\section{Review of Literature}

There are uncountable national as well as international literature regarding women empowerment and education. In the present study, a short review of literature is referred which highlights on the importance of education in empowerment of women and developing women entrepreneurs.

Mira Seth (2001) depicted from her study entitled "Women and Development, the Indian Experience" and concluded that future of the girl child gets further endangered if her mother is illiterate, for an educated mother will always educate her daughter but an illiterate mother may not.

Ramanujam and Thenmozhi (2006) stated that as education is a major source of power, women should be given proper education, It develops the personality of women exposing them to the word of books, peers, teachers and public at large. It is being increasingly felt that empowerment of women will enable a greater degree of self-confidence, a sense of independence and capability to resist discrimination imposed by the male dominated society.

G. Malyadri (2014) in her study on Role of women Entrepreneurs in the Economic Development of India indicates that women entrepreneurs are found to be working in difficult situations when compared to their male counterparts and factors like political instability, poor infrastructure, high production costs and nonconductive business environment are affecting women entrepreneurs more than men.

Hina Shah and Punit Saurabh (2015) in their study on Women entrepreneurship in developing countries conclude that even though there have been some successful strategies towards the development of women entrepreneurship, there needs to be done more towards this so that such ventures can help in poverty alleviation of South Asian region.

\section{Education and Women Empowerment}

Education helps the women not only in gaining knowledge but also enables her to earn a living. Every woman has got her own aspiration which may be high or low, but education helps to maintain a balanced aspiration knowing her interest, ability and potential which further helps her to choose a correct field of her work. Educated girls and young women are more likely to know their rights and to have the confidence to claim them. Education of a women leads to a better family and ultimately an ideal society into a progressive nation. Education improves job opportunities and increases economic growth of the country.

Education is a milestone for women empowerment because it enables them to respond to opportunities, to challenge their traditional roles and to change their lives. It is accepted that education is one of the most important means of empowering women with the knowledge, skills and selfconfidence necessary to participate fully in the development process. Educated women try to get empowered by participating in social, political, cultural, and religious work. They enhance the quality to grow in the society and helps in educating the next generations. Thus, she plays a significant role in the development and contributes significantly to the social and economic reconstruction of the nation.

\section{Women Entrepreneurs in various fields of Maharashtra State}

Active participation of women in economic activity of various fields and decision making is very much needed to increase the life style. Skill, knowledge-based education enables to change the role of women from homemaker to job maker. Education enhances knowledge which enables access to resources and opportunities.

According to the Sixth Economic Census (2013) of Maharashtra State, the number of establishments owned by women entrepreneurs was $6,64,300$. Out of which 3, 46, 216 were located in rural areas and the remaining 3, 18, 084 were located in urban areas. Of these total establishments under women entrepreneurs, about $26.86 \%$ belonged to agricultural activities, with livestock dominating with a share of $25.26 \%$. Among non-agricultural activities owned by women entrepreneurs, manufacturing and retail trade were the dominant ones, corresponding percentages being $27.02 \%$ and $20.63 \%$ respectively.

Agricultural Entrepreneurs are involved in agricultural activities. They manage and develop agricultural products. It is a strategic development in the agriculture sector and also helpful in the development of remote areas. Agricultural and business related to agriculture is also known as Agribusiness. It involves all the steps required to send an agricultural good to market, namely production, processing, and distribution, whereas, Non-agricultural activities consists of Manufacturing, Trade, Education and Other Services. The table below depicts the economic activities as per establishments owned by women entrepreneurs.

Top Five Economic Activities by Women Entrepreneurs

\begin{tabular}{|c|c|c|}
\hline Sr. No. & Economic Activities & Percentage \\
\hline 1. & Agricultural Activities & $26.86 \%$ \\
\hline \multicolumn{3}{|c|}{ Non-Agricultural Activities } \\
\hline 2. & Manufacturing & $27.02 \%$ \\
\hline 3. & Trade & $21.46 \%$ \\
\hline 4. & Education & $03.72 \%$ \\
\hline 5. & Other Services & $20.94 \%$ \\
\hline
\end{tabular}

Source: Sixth Economic Census (2013) of Maharashtra State 

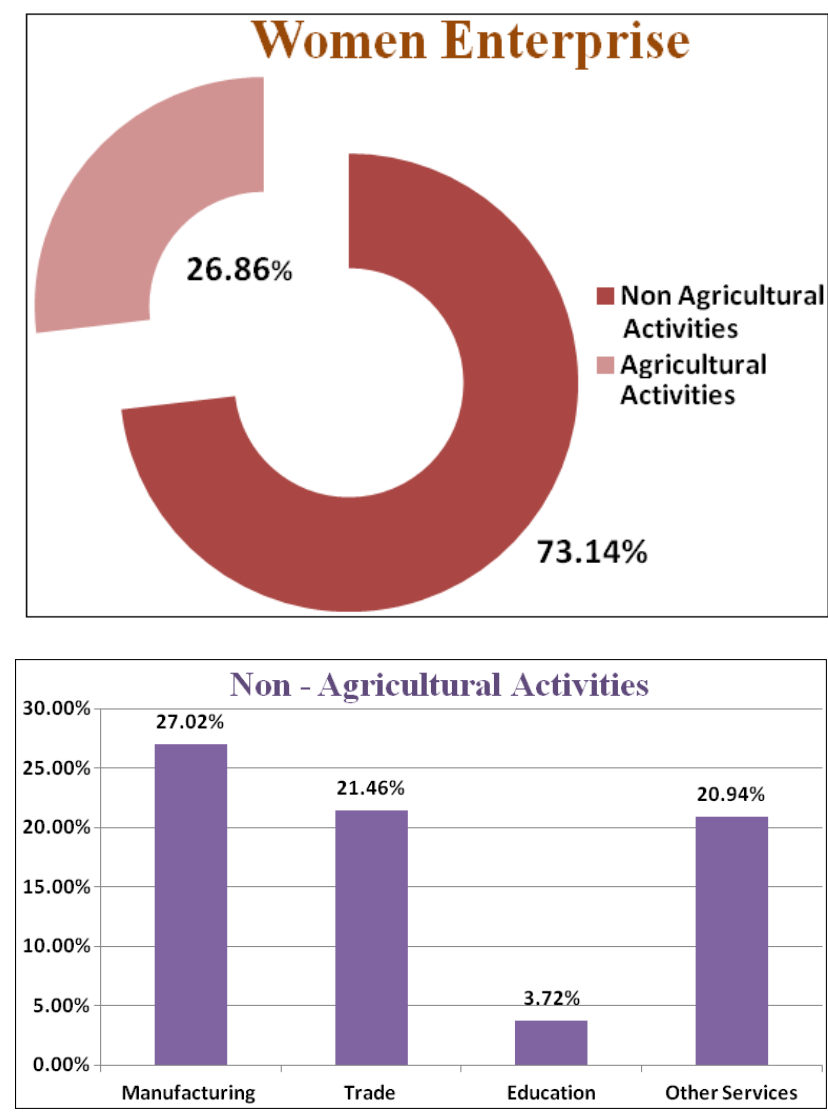

It can be seen from the table and graphs that women entrepreneurs belonging to agricultural activities was $26.86 \%$ and $73.14 \%$ was for non-agricultural activities. In non-agricultural sector the maximum $27.02 \%$ women's owned enterprise were involved in Manufacturing, whereas, minimum only $3.72 \%$ were involved in Educational activities. In activities owned by non-agricultural women entrepreneurs, manufacturing and trade were the dominant ones, corresponding percentages being $27.02 \%$ and $21.46 \%$ respectively.

Top Five Districts by Number of Establishments under Women Entrepreneurship

\begin{tabular}{|c|c|c|}
\hline Sr. No. & Name of District & Percentage \\
\hline 1. & Kolhapur & $15.07 \%$ \\
\hline 2. & Satara & $08.19 \%$ \\
\hline 3. & Pune & $07.97 \%$ \\
\hline 4. & Solapur & $07.62 \%$ \\
\hline 5. & Mumbai Suburban & $07.29 \%$ \\
\hline
\end{tabular}

Source: Sixth Economic Census (2013) of Maharashtra State

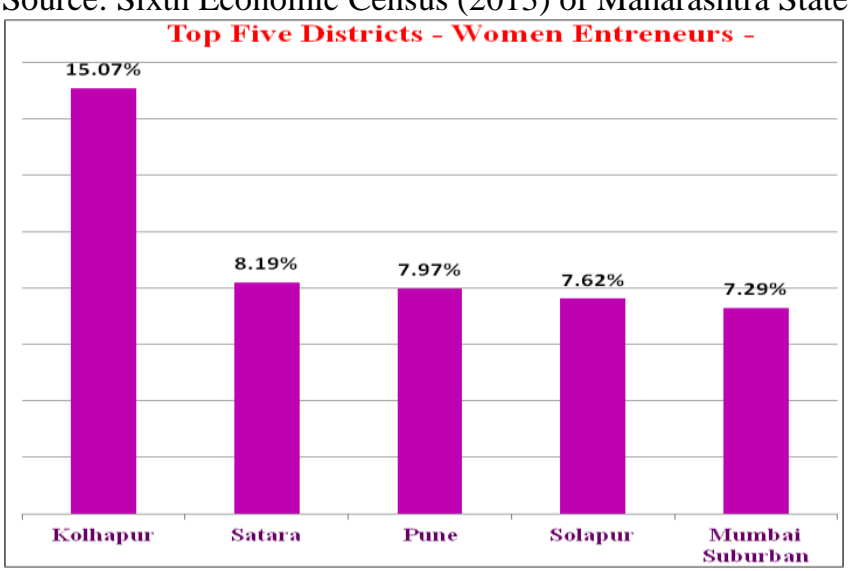

It can be seen from the above table that Kolhapur is at the top in women entrepreneurship at $15.07 \%$ whereas other remaining districts and in the range of $7 \%$ to $8 \%$ only.

The Sixth Economic Census (2013) of Maharashtra State shows that about 5, 80, 337 establishments (87.36\%) were operated without hired workers and only 83, $963(12.64 \%)$ were operated with hired workers. The percentage of establishments without hired workers in rural areas was $93.56 \%$, whereas, it was $80.62 \%$ in urban areas. The number of women establishments involved in agricultural activities was $1,78,422$ constituting $26.86 \%$ of the total number of establishments owned by women.

The figures clearly indicate that maximum women enterprises are operated solely. The reason behind it is that their businesses are small and hence they cannot afford to hire workers.

\section{Status of Women Entrepreneurs in 2021:}

Women have a natural gift of rising to challenges and emerging successful, at the workplace they always strive to go beyond and achieve more. Gone are the days when women were confined to domesticity and making household the first priority. The ability to juggle many roles at work and at home make women better at managing time and priorities, leading to almost doubling their efficiencies and leading to an overall impact on the country's growth and future.

Now-a-days women enter not only in selected professions but also in professions like trade, industry and engineering. Women are also willing to take up business and contribute to the Nation's growth. There role is also being recognized and steps are being taken to promote women entrepreneurship. Women entrepreneurship must be moulded properly with entrepreneurial traits and skills to meet the changes in trends, challenges global markets and also be competent enough to sustain and strive for excellence in the entrepreneurial arena.

Despite the barriers, women, especially young women, are at the forefront of diverse and inclusive movements for social change. It is a prerequisite to finally fully utilize the power of women leadership to realize a more equal, more inclusive, and more sustainable future.

It is well known that India has the world's third largest startup ecosystem. However, the percentage of women entrepreneurs is comparatively less to their male counterparts. India has a total of 58.5 million entrepreneurs and 8.05 million of those are women entrepreneurs, which adds up to only $14 \%$ women entrepreneurs in Indian business settings.

In the last couple of years, this scenario is changing and things are looking positive for women entrepreneurs. Women are consistently raising the benchmark and are transforming the world of start-ups.

India's economic and geographic diversity, successful intervention requires understanding and tailoring initiatives for budding and established entrepreneurs. There are six 
dominant segments with varying demographics, motivations, ambitions and constraints. The percentage of six dominant segments of women owned enterprises are-

Scaler: $\sim 1 \%$, Urban small business owners: $\sim 6 \%$, Rural small business owners: $\sim 8 \%$, Urban solopreneurs: $\sim 31 \%$, Rural solopreneurs: $\sim 38 \%$ and Rural agripreneur: $\sim 16 \%$.

Understanding these segments will help identify the right opportunities and frame the necessary institutional, economic and social support for entrepreneurship.

Since the pandemic started showing its effects in India, women-run Self-Help Groups swung into action to provide ancillary services and support the fight against the pandemic. The Ministry of Rural Development told LiveMint that SHGs across 13 states manufactured over 54 million masks and 2.8 trillion litres of sanitisers. Apart from this, SHGs across the country have taken the lead in running community kitchens, sensitising people about health and hygiene, delivering essential supplies and busting misinformation.

COVID-19 has led to a massive decline in revenue for women-owned businesses. As per a recent research survey by Bain and Company, Google, and AWE Foundation, 73\% of women entrepreneurs have been negatively impacted with almost $20 \%$ facing a complete wipe out in their revenues. Most businesses have not returned to pre-COVID-19 levels.

According to a survey by Digital Financial services firm, women are actively getting involved in financial planning decisions and are also investing more, pushed by the covid crisis and uncertainties. This clearly indicates self-reliance and how far women have come when it comes to financial matters and taking the lead. A research conducted by Bain \& Company, Google, and AWE Foundation surveyed 350 women solopreneurs and small business owners in urban India. The survey reveals that start-ups led by women founders are resilient and quick to adapt to changes, meet challenges and new trends. It also highlighted that women are also better at efficient multitasking than men, which helps them focus on the larger perspective of a business rather than on only one aspect. According to a survey conducted recently by JobsForHer, in association with SPJIMR, it was found that 60 percent of women consider reskilling or up-skilling as the preferred path they would take to restart their career.

\section{Suggestions}

Following are the suggestions based on the above study which can boost the women entrepreneurs for succeeding in 2021:

1) Women entrepreneurs need more support from their families and social circles to pursue their entrepreneurial ambitions and develop courage as well as self-confidence among them.

2) Collaboration with NGOs, CSOs and other volunteers can educate women and their families about the available government policies and can help to create higher awareness for setting up new venture.
3) Ensure training on management skills, extending vocational education, online education in entrepreneurship training and development programmes for women in various fields can increase the percentage of women entrepreneurs. It can bring a drastic change in women's rights, security, dignity and their overall empowerment.

4) Further, promoting change in perception about women's potential, and highlighting the benefits of women entrepreneurship for the family's overall societal status and lifestyle can inspire families to encourage entrepreneurship among women.

5) A more equal distribution of household tasks, greater financial backing from banks and support to diversify into more sustainable sectors, could make a huge difference to women entrepreneurs in their ongoing progress.

6) Interaction with successful women entrepreneurs of the era will help young women entrepreneurs to get motivated and committed for their work. They should also focus on digital inclusion.

7) Women entrepreneurs should go on increasing knowledge related to their enterprise such as the demand and supply, market requirements, information related to competitors' policies etc.

8) Regeneration of women entrepreneurship is the prerequisite at present which is only possible by increasing literacy, spreading knowledge.

9) Providing space in dialogues -women to women and women to men in business capabilities and partners. Encouraging women's participation in decision-making in every activity can help women entrepreneurs to achieve their goals.

10) Providing concessions to women entrepreneurs from tax burden will help them to grow stable, gain confidence and success in their business.

\section{Conclusions}

One of the most significant transformations in education in India over the past several decades is the drastic increase in women's higher education in various fields. The study indicates that the education has showed the ways of uplifting the standard of living among the women's. Acceleration due to education will bring about a full transformation of India's women entrepreneurship landscape.

Education to women will put India at par with several emerging and advanced economies where more than $40 \%$ of all enterprises will be women-owned. Further, the total employment will bridge nearly $25 \%$ of the jobs required to absorb the working-age population in 2030. Given the continued scarcity of education, work opportunities, entrepreneurship will allow women to be self-sustaining, giving them greater flexibility and control in comparison to salaried employment and also creating jobs.

We are witnessing a 'New India' where we are seeing women emerge as efficient multi-taskers. In the face of the COVID-19 pandemic, the year 2020 was a remarkable year for women in leadership. More women assumed the leadership of vast and influential companies while managing the housework as well. According to the World Bank, 
doubling the percentage of women in the workforce would boost India's growth rate from 7.5 to $9 \%$ and raise the country's GDP to US $\$ 700$ billion by 2025 .

The COVID-19 pandemic presents opportunity for young women entrepreneurs to start their new enterprise which will not put burden of shocks in the future. Lastly despite of such crisis, numerous opportunities have emerged related to healthcare, financial instruments, education, supply chains, entertainment and culture. These are some of the sectors in need of innovative ideas and developments in the current situation where women's of $21^{\text {st }}$ century can emerge as successful entrepreneurs.

\section{References}

[1] Alva, A. and Hans V. B. (2013). "Higher Education in India - Opportunities, Changes and Challenges". Available at http: //ssrn. com/abstract $=2203706$

[2] Bain \& Company and Google. "Powering the Economy with Her, Women Entrepreneurship in India", February 18, 2020.

[3] Mira Seth (2001). "Women and Development: The Indian Experience", Thousand Oaks, California: Sage 2001.

[4] G. Malyadri (2014). "Role of Women Entrepreneurs in the Economic Development of India", Indian Journal of Research, Vol.3, Issue 3, March 2014.

[5] Hina Shah and Punit Saurabh (2015). "Women Entrepreneurship in Developing Countries", Technology Innovation Management Review, (Volume 5, Issue 8), August 2015

[6] K. N. Ramanujam and R. Thenmozhi (2006). "Empowerment of women", Kisan World, pp.62, June, 2006.

[7] Naghma Mulla, "Challenges and Opportunities - Why Women Entrepreneurship lags in India Despite Governmental Initiatives", Timesnownews. com, $19^{\text {th }}$ Nov, 2020.

[8] Report on $6^{\text {th }}$ Economic Census of Maharashtra State, Directorate of Economics and Statistics, Planning Department, Government of Maharashtra, Mumbai.

[9] Shilpa Khanna Thakkar, "How Indian Women Entrepreneurs Are Making Their Mark In India's Booming Startup Industry", Business World, June 4, 2021.

[10] Veena R. Humbe (2014), "Role of Social Media in Marketing of Handloom Products", International Journal of Science and Research (IJSR), Volume 3 Issue 7, July 2014, pp.136-139.

[11] Veena R Humbe (2016), "Role of Women in sustaining National Heritage With Special Reference to Maharashtra Handloom Industries Manufacturing Paithani", Women in Science and Technology, Creating Sustainable Career, Indian Journal of Technical Education, Publisher: Gujarat Technological University, pp.1-8, 2016 